Canadian Journal of Fisheries and Aquatic Sciences

Canadian Science Publishing

Journal canadien des sciences halieutiques et aquatiques

\title{
Population biology of infectious diseases shared by wild and farmed fish
}

\begin{tabular}{|r|l|}
\hline Journal: & Canadian Journal of Fisheries and Aquatic Sciences \\
\hline Manuscript ID & cjfas-2016-0379.R1 \\
\hline Manuscript Type: & Perspective \\
\hline Date Submitted by the Author: & $28-$ Oct-2016 \\
\hline Complete List of Authors: & $\begin{array}{l}\text { Krkošek, Martin; University of Toronto, Department of Ecology and } \\
\text { Evolutionary Biology }\end{array}$ \\
\hline Keyword: & $\begin{array}{l}\text { DISEASES < General, AQUACULTURE < General, EPIDEMIOLOGY < } \\
\text { General, MIGRATION < General, FISHERY MANAGEMENT < General }\end{array}$ \\
\hline &
\end{tabular}

SCHOLARONE ${ }^{\text {IM }}$

Manuscripts 


\section{Population biology of infectious diseases shared by wild and farmed fish}

2 Martin Krkošek

3 Department of Ecology and Evolutionary Biology, University of Toronto, 25 Harbord St,

4 Toronto, ON, M5S 3G5

5 Salmon Coast Field Station, Simoom Sound, BC, V0P 1S0

7 Abstract

8 Global fisheries landings ceased increasing decades ago, causing an increasing shortfall in wild

9 seafood supply and an expansion of aquaculture. The abundance of domesticated fishes now

10 dwarfs related wild fishes in some coastal seas, changing the dynamics of their infectious

11 diseases. Transport and trade of seafood, feed, eggs, and broodstock bring pathogens into new

12 regions and into contact with naïve hosts. Density-dependent transmission creates threshold

13 effects where disease can abruptly switch from endemic to epizootic dynamics. Hydrodynamics

14 allow pathogens to disperse broadly, interconnecting farms into meta-populations of

15 domesticated host fish in regions that also support related species of wild fish. Spill-over and

16 spill-back dynamics of pathogen transmission between wild and farmed fish can create novel

17 transmission pathways or bioamplify pathogen abundance, potentially depressing or endangering

18 wild fish. Mortality from natural predator-prey interactions may be synergistic or compensatory

19 with these increased infections. Domestic environments may favour the evolution of undesirable

20 pathogen traits, such as virulence and drug resistance, leading to the emergence of strains that

21 cause high mortality and/or evade treatment. Overall, these changes to the dynamics of infectious

22 disease in coastal seas impose new constraints on the sustainability of both wild and farmed fish. 


\section{Introduction}

24 It has been about 30 years since global fisheries landings stopped increasing (Figure 1)(FAO

25 2016). While fisheries and conservation science have contested the sustainability of marine

26 resource use (Pauly et al. 1998, Myers and Worm 2003, Walters 2003, Worm et al. 2009, Branch

27 et al. 2010), it has become clear that fisheries have not and cannot keep pace with the growing

28 global demand for seafood (FAO 2016). The resulting deficit in the supply of wild seafood has

29 caused a switch from hunting to farming (i.e., aquaculture) in coastal seas (Figure 1) (Goldburg

30 and Naylor 2005, Duarte et al. 2007). Overall, aquaculture now supplies as much seafood for

31 human consumption as global fisheries (FAO 2016), and trends in fish production indicate

32 continued saturation of aggregate fisheries production and rapid growth in domesticated marine

33 and diadromous fish populations (Figure 1).

34 With this blue revolution, some coastal seas are becoming managed for aquaculture

35 production (Goldburg and Naylor 2005). Large populations of domesticated fish now inhabit

36 some ocean regions, where marine ecosystems provide both services and disservices to the

37 aquaculture industry. Services include the provisioning of fresh seawater and the assimilation of

38 waste, whereas disservices include a diversity of parasite infections (ranging from viruses to

39 metazoans) that originate from sympatric wild fishes (Nowak 2007, Walker and Winton 2010b).

40 Infectious diseases cost shellfish and finfish aquaculture industries billions annually and pose

41 disease risks for wild fish (Krkošek et al. 2006, Lafferty et al. 2015). The population biology of

42 fish and parasites should alert us to changes in the epidemiology of infectious diseases in a future

43 of domesticated seas (Grenfell and Dobson 1995, Mennerat et al. 2010).

44 In this paper I discuss the ecological and evolutionary theory of marine infectious

45 diseases in the context of global trends in aquaculture and fisheries. To be clear, I refer to

46 parasites as the full assemblage of microparasites (e.g. viruses and bacteria) and macroparasites 
47 (e.g. helminthes and sea lice). I begin by situating fisheries and aquaculture within the

48 framework of emerging infectious diseases (EID), and then discuss the main ecological and

49 evolutionary dynamics that characterize the population biology of these host-parasite systems.

50 My focus is on population level theory of parasites and wild fish, and how the introduction of

51 domesticated fish may affect dynamics. I conclude with a discussion of how the ecological and

52 evolutionary dynamics described may affect future epidemiology of marine infectious diseases

53 given a global context of saturated fisheries and expanding aquaculture.

55 Emerging Infectious Diseases of Fish

56 The emergence of infectious diseases is often traced to the intensification of parasite

57 transmission among humans, domesticated animals, and wildlife (Daszak et al. 2000). Diseases

58 such as plague, avian flu, HIV, and Ebola, are all examples of emergence and spread in this way.

59 The growth of domesticated fish populations raised in coastal seas has created the spill-over

60 (parasite transmission from wild to farmed animals) and spill-back (parasite transmission from

61 farmed to wild) dynamics that are key ingredients for disease emergence (Daszak et al. 2000).

62 Further, there are unique characteristics of marine epidemiology that may facilitate disease

63 emergence and spread in coupled wild and farmed fish populations.

64 The dynamics of infectious diseases in the oceans differ from those on land in several

65 ways (McCallum et al. 2004). First, ocean environments have fewer barriers to the movement of

66 hosts and pathogens. Second, large migrations of fish are common, and ocean currents can carry

67 both hosts and pathogens for long distances. Third, common behaviours such as aggregation of

68 fish hosts in shoals and schools can further facilitate disease spread. As a result of these

69 differences infectious diseases have rates of spatial spread in the oceans that are one to two

70 orders of magnitude faster than on land (McCallum et al. 2003). For example, herpes epidemics 
71 of Australian pilchards in the 1990s (Jones et al. 1997, Gaughan 2001) spread at 10,000 km per

72 year (McCallum et al. 2003).

73 Analyses have shown that cases of marine infectious disease are increasing for some host

74 taxa but decreasing for other taxa (Lafferty et al. 2004, Ward and Lafferty 2004). Overall,

75 diseases in wild marine fish have been decreasing (Ward and Lafferty 2004), potentially because

76 of a process known as fishing out parasites (Dobson and May 1987, Wood et al. 2010). The

77 reduction in wild fish population sizes due to fishery harvests has the potential consequence of

78 reducing the transmission success of parasites that have density-dependent transmission.

79 Comparisons have suggested that fish populations in marine protected areas have higher

80 abundances and diversity of parasites (Lafferty et al. 2008).

81 At the same time, however, infectious diseases of farmed fish are a significant

82 impediment for aquaculture production (Walker and Winton 2010a, Lafferty et al. 2015). A

83 recent review of EID (there defined as emergence of previously unknown diseases, or spread of

84 existing disease into new host species or geographic locations) in wild vertebrates indicated that

85 freshwater and marine fishes have the highest rates of disease emergence amongst vertebrates,

86 which is at least partially because they are the most speciose group (Tompkins et al. 2015). The

87 most common mechanism of EID in other taxa was human-mediated transmission whereas for

88 wild fish, it was mostly direct transmission between wild and domesticated fish. Approximately

$8975 \%$ of new and ongoing cases of EIDs in wild fish since 2000 have co-occurred in aquaculture.

90 These patterns contain a sample bias for temperate species of commercial importance, like

91 salmon.

92 Overall, these trends of disease cases in wild and farmed fish suggest that coastal seas

93 utilized for fishing and aquaculture have seen a decline in wild fish stocks and their parasites due

94 to fisheries effects on fish stocks, but an increase in domesticated fish populations and their 
95 parasites due to aquaculture expansion. In seas where wild and farmed fish share parasites, this

96 creates parasite-mediated apparent competition that is modified by economic and policy

97 feedbacks. Theory of such interactions is currently lacking but is needed to understand the

98 dynamics of such coupled human and natural systems. In the next sections I discuss key

99 ecological and evolutionary processes that are likely to modify the epidemiology of infectious

100 diseases in coastal seas due to the transmission of parasites between wild and domesticated fish.

\section{Parasite Dispersal}

103 Hydrodynamics of coastal seas can allow parasite transmission to occur over long distances.

104 Physical hydrodynamic variables such as salinity, temperature, UV radiation, wind, river

105 discharge, and tidal currents all can affect the distance that parasites can spread in a coastal

106 marine environment (Garver et al. 2013, Foreman et al. 2015). For example, the dispersal of sea

107 lice from salmon farms can extend for $30 \mathrm{~km}$ or more into the surrounding ecosystems (Krkošek

108 et al. 2005). Hydrodynamic models of parasite dispersal that incorporate the dependency of

109 parasite demographic rates on environmental variables have been useful for studying the spatio-

110 temporal dynamics of parasite dispersal among fish farms (Amundrud and Murray 2009, Stucchi

111 et al. 2011). Thus, there is a need for a regional perspective on marine epidemiology, in which

112 the spatial scale includes metapopulation structure where subpopulations of parasites in fish

113 farms are interconnected (Aldrin et al. 2013). As a corollary, the population dynamics of

114 parasites shared between wild and farmed fish will likely be organized at regional scales that

115 involve aggregations of aquaculture activity and wild fish habitat/migrations.

\section{Host Migration}


118 Migrations of marine fish species are common, and migrations of host populations have a

119 number of implications for infectious disease dynamics including migratory culling, escape,

120 stalling, and allopatry (Altizer et al. 2011). Migratory culling refers to situations where infected

121 individuals are lost from the migratory population due to mortality or an inability to keep pace

122 (Bradley and Altizer 2005). Migratory culling can lead to declines in both host population size

123 and parasite abundance during migration. Migratory escape refers to the situation where hosts

124 migrate to new environments where infection risk is lower because local parasite abundance has

125 not yet accumulated (Hall et al. 2014). Alternatively, a negative effect of infection on migration

126 speed may create a dynamic that may result in a slowing or stoppage of the migration, depending

127 on how the collective behavior of hosts in a migrating population responds to parasitism.

128 Migratory allopatry describes a situation where the natural host lifecycle involves a migration

129 that separates age-classes, effectively stopping transmission from old to young individuals for

130 long periods during ontogeny (Krkošek et al. 2007).

131 Aquaculture may interact with these migratory processes in a variety of ways. In

132 particular, it can situate large populations of domesticated hosts on the migration routes of wild

133 fish (Figure 2), creating opportunities for transmission to occur in phases of the ontogeny of wild

134 fish for which there is little evolutionary history or pre-adaptation to elevated levels of parasite

135 exposure (Krkošek et al. 2005). Fish with life histories that use coastal habitats for juvenile

136 feeding and growth or with life histories entirely situated in coastal habitats are particularly

137 vulnerable to parasites whose levels may be elevated by the growth of domesticated fish

138 populations. Migratory stalling may also cause migrating fish populations to extend their stay in

139 habitats where parasite abundance is high, potentially creating a positive feedback between

140 parasite levels, slowing migration speed, and mortality. In addition, parasite exposure may alter

141 the timing and duration of migrations. For example, there is evidence of migratory escape in sea 
142 trout, where they prematurely terminate their marine migration and return to freshwater habitats

143 to escape high sea-louse parasite abundances (Birkeland and Jakobsen 1997). Also, sea lice

144 infection experienced by juvenile Atlantic salmon is associated with delayed maturity and

145 therefore delayed spawning migrations of adult salmon (Vollset et al. 2014).

\section{Parasite translocation}

148 A common mechanism for EID in coastal marine fish is the transport of seafood products, feed,

149 eggs, or broodstock that can contain parasites. A consequence is that parasites become

150 introduced into domesticated and wild fish populations in new regions, contributing to spatial

151 spread of infection. Further, the recipient host fish populations may have little evolutionary

152 history with the parasites (i.e. naïve host populations vulnerable to epizootics).

153 For example, it is thought that frozen whole pilchards that are imported to Australia as

154 feed for tuna ranches were a source of two epidemics of herpes virus that swept through

155 Australian and New Zealand pilchard stocks in the late 1990s (Jones et al. 1997, Gaughan 2001).

156 Those epidemics spread at 10,000 km per year (McCallum et al. 2003), causing mass mortality

157 of $\sim 30,000$ tonnes in Western Australia in 1998-99, (Gaughan et al. 2000) and a 75\% decline in

158 pilchard spawning biomass (Ward et al. 2001b). Such parasite induced mass mortality can have

159 cascading ecological effects; the pilchard die-off led to the expansion of competitor species

160 (Ward et al. 2001a), reproductive failure in penguins (Dann et al. 2000), and diet shifts in

161 gannets (Bunce and Norman 2000).

162 In farmed fish, epidemics of infectious salmon anemia virus (ISAv) in Chilean salmon

163 farms have been traced to the introduction of an endemic Norwegian strain (Kibenge et al. 2009),

164 causing a $75 \%$ decline in farmed salmon production from the world's second biggest producer

165 (Asche et al. 2009). Both ISAv and Piscine Reovirus (PRV - the agent associated with heart and 
166 skeletal muscle inflammation disease) (Palacios et al. 2010) are considered exotic to the North

167 Pacific Ocean, but PCR tests of farmed and wild salmon have indicated that strains of these

168 ancestrally Norwegian viruses may now be present in both wild and farmed salmon in British

169 Columbia (Kibenge et al. 2013, Marty et al. 2015, Kibenge et al. 2016). These examples

170 underscore the need for continuing and increasing biosecurity practices that focus on the trade

171 and movement of seafood products - including aquaculture products, feed, eggs, and broodstock

172 - at regional and global scales.

174 Host-density thresholds

175 The population dynamics of infectious diseases commonly involve threshold effects due to

176 density dependent transmission (Grenfell and Dobson 1995, Lloyd-Smith et al. 2005). Density

177 dependent transmission occurs for diseases where the transmission rate is an increasing function

178 of the density of hosts. Exceptions occur where parasites retain high levels of transmission

179 success even if hosts are not abundant because of host aggregation (e.g. sexually transmitted

180 diseases) as well as vectors that actively search for hosts (e.g. mosquitos). In these cases, the

181 transmission rate is frequency dependent (i.e. it depends on the prevalence of infection but not on

182 the density of hosts). For fish, it is common for macroparasites to have an indirect lifecycle that

183 involves invertebrate intermediate hosts, but active vector-borne transmission appears to be

184 relatively rare. Due to external fertilization, sexually transmitted diseases are likely to also be

185 rare for fish. These patterns mean that parasite life-histories that have density dependent

186 transmission are likely to make up the majority of fish diseases, although such patterns have not

187 been empirically quantified.

188 Density dependent transmission creates a threshold effect in the population dynamics of

189 disease. At low host densities an infection will fade out after being introduced, whereas at high 
190 host densities an initial infection will, on average, spread to at least one or more other hosts.

191 There is therefore a critical host density threshold that separates two sets of dynamics, one where

192 diseases fade out and another where diseases spread. Because the critical host density is a

193 function of environmentally-dependent demographic parameters, the threshold itself is also

194 likely to be a function of such factors as temperature and salinity (e.g. sea lice), or UV radiation

195 (e.g. degradation of viruses). For fisheries and aquaculture, sea lice and salmon are an example

196 of a macroparasite-host system that has density dependent transmission and thresholds that

197 divide endemic and epidemic conditions (Frazer et al. 2012, Jansen et al. 2012).

198 A simple theoretical example using a susceptible-infected epidemiological model

199 suggests how microparasite (e.g. viruses and bacteria) dynamics may switch from a low endemic

200 state to epizootic dynamics as aquaculture production increases (Figure 3). Infection levels

201 initially occur at a low endemic state that is maintained by pathogen immigration when farmed

202 fish abundance is below the threshold $\left(N<N_{c}\right)$. Dynamics then transition into epizootic when

203 farmed fish abundance exceeds the host density threshold $\left(N>N_{c}\right)$. Empirically, the dynamics

204 of microparasitic disease in farmed fish will be more variable than this simple model, due to the

205 effects of environmental and demographic stochasticity, variation in management and biological

206 variables, and spatial factors discussed earlier such as parasite dispersal, fish migration, and

207 metapopulation dynamics. Nonetheless, the model illuminates how the epidemiology of disease

208 can change abruptly in response to gradual growth in domesticated fish populations.

$210 \quad$ Allee effects

211 Allee effects - reduced fitness at low population abundance - may create other thresholds in the

212 population dynamics of host-parasite systems. Whereas the critical host density thresholds

213 discussed above involve dynamics where parasite demography is dependent on host density, 
214 Allee effects refer to situations where parasite demography depends on parasite abundance and

215 where host demography depends on host abundance.

216 For parasites, demographic Allee effects may occur through at least two mechanisms.

217 Mate limitation likely occurs for dieocious parasite species (males and females are separate

218 individuals) because the probability a male and a female occur in the same host decreases at low

219 parasite abundances (May 1977). Separately, Allee effects may occur for parasites that have

220 positive-sloped dose-response curves (probability of pathogen invasion in an individual host is

221 an increasing function of the abundance of pathogens to which it is exposed) (Regoes et al.

222 2002). These mechanisms can create a breakpoint in the parasite population dynamics that

223 divides initial conditions under which a large founding parasite population will grow versus

224 those in which a small initial number of parasites will fail to establish new infections in the host

225 population. Thresholds arising from Allee effects in parasite demography may slow the spread of

226 infection between wild and farmed fish populations and provide a target for managing parasite

227 abundance (Krkošek et al. 2012).

228 For wild fish exposed to parasites from a reservoir host population, an Allee effect can

229 occur because the abundance of parasitic infectious stages is decoupled from host abundance and

230 so large numbers of parasites can remain in the environment and become concentrated on the

231 few remaining hosts (Krkosek et al. 2013). Here, the dynamics are conceptually analogous to the

232 Allee effect that occurs in the population dynamics of a prey population subject to predation by a

233 type II predator (McLellan et al. 2010). Thus for wild fish exposed to parasite transmission from

234 a reservoir domesticated host population, the emergent Allee effect may contribute to population

235 decline and/or endangerment.

236

237 Foodweb dynamics

https://mc06.manuscriptcentral.com/cjfas-pubs 
238 In many infectious disease systems, there are multiple host populations that interact directly and

239 indirectly within a foodweb. An example of a negative indirect interaction involving hosts is

240 apparent competition in which a parasite that is shared by two host populations creates a negative

241 correlation between the demographies of the two host populations, creating a false impression

242 that the two hosts are competitors (Hatcher et al. 2012). Two examples of parasites with multi-

243 host dynamics that also involve domesticated fish are infectious hematopoietic necrosis virus

244 (IHNv) and the sea louse Caligus clemensi, both of which infect salmonids, herring and other

245 species. Even for salmonid-specific parasites, such as salmon lice, there are multiple salmon

246 species that may interact via competition, predation, and shared parasites.

247 The indirect effects created by foodweb interactions among hosts can also involve

248 predators that exacerbate or counteract parasitism in multi-host communities. If predators have a

249 type-II functional response (i.e., attack rate is limited by the predator's capacity to process prey),

250 in which the attack rate increases with the parasite load of prey, then predators may exacerbate

251 mortality rates from parasites consuming more hosts when host abundance is low, but may also

252 reduce the overall parasite load without changing overall mortality when hosts are abundant by

253 focusing predation on the fraction of infected hosts (Krkošek et al. 2011) (Figure 4). In

254 communities with both parasite and predator-mediated apparent competition, the combination of

255 predator selectivity and parasite effects on predation risk of prey may result in predation

256 becoming concentrated on the preferred prey, exacerbating mortality in the preferred host species

257 but also releasing the less-preferred host from predation (Peacock et al. 2014, Peacock et al.

258 2015).

259

260 Climate Change 
261 Parasite demographic rates and fish population sizes and ranges are all affected by variation in

262 ocean conditions. Theory and empirical work indicate that parasites and hosts have optimal

263 thermal ranges, and so depending on the juxtaposition of host and parasite responses to changes

264 in climate, the outcomes may involve range shifts and local decreases or increases in the

265 intensity of an infectious disease (Lafferty 2009, Molnar et al. 2013). For example, some cold-

266 water diseases of fish may become less problematic or may no longer constrain habitat used by

267 wild and farmed fish as temperature increases (Nematollahi et al. 2003). For other disease

268 systems, parasite demographic rates may accelerate with small increases in temperature,

269 generating faster population growth and elevated risk of epizootics (Groner et al. 2014, Bateman

270 et al. 2016). Climate variation may also have important implications for parasite dispersal and

271 persistence in the marine environment (O'Connor et al. 2007), since the demography of infective

272 stages depends on temperature, salinity, UV radiation and other physical factors (Groner et al.

273 2014, Foreman et al. 2015). Both long-term and seasonal climate variation may therefore

274 contribute substantially to disease outbreaks or the release of farmed or wild fish populations

275 from disease burden.

277 Virulence

278 Evolutionary theory indicates that increases in host density should select for increased levels of

279 virulence (reduction in host fitness due to the parasite) (Day 2001, Day and Gandon 2007). This

280 is the result of a trade-off between parasite transmission and parasite-induced host mortality. In

281 an environment of low host abundance, natural selection will favor a parasite phenotype that has

282 low virulence so as to not kill its current host before the parasite's offspring are transmitted to a

283 new host. In an environment where host density is high, transmission success of individual

284 parasite offspring becomes saturated and so parasite phenotypes that have high fecundity are 
285 favoured, but that usually occurs at the expense of host demography, typically survival. Further

286 ecological factors such as predation or food limitation that differ between wild and domesticated

287 environments may cause the transmission-virulence trade-off curves to shift in favour of

288 increased virulence in domesticated environments (Figure 5). For fisheries and aquaculture, there

289 is evidence that trait variation and conditions in domesticated environments can select for

290 increased virulence of parasites on fish farms, including bacterial (Pulkkinen et al. 2010) and

291 macroparasitic diseases (Mennerat et al. 2012).

Kennedy et al. (2016) identified eight factors that may lead to selection for increased

293 virulence of pathogens in aquaculture systems. These included four related to intensive

294 aquaculture operations: high-density rearing of farmed fish, which aids transmission; shortened

295 rearing cycles of farmed fish, which selects for faster transmission rates of parasites; low genetic

296 diversity of broodstock, which allows invasion of virulent specialist strains of parasites; and

297 endemic infections in farmed stocks, which creates opportunities for adaptation of parasites. An

298 additional four factors relate specifically to disease control practices: incomplete vaccination,

299 which creates dynamics similar to the endemic infection described above; breeding for

300 resistance, which because it doesn't completely prevent infection or transmission can similarly

301 select for increased virulence; chemotherapy, which can select for virulence if the mechanism

302 that selects for drug resistance is also linked to virulence; and management practices that favour

303 horizontal transmission (among conspecifics) over vertical transmission (parent to offspring).

\section{Drug resistance}

306 Parasites of farmed fish have evolved resistance to antibiotics and pesticides used in fish health

307 management, creating a need for new medicines and treatment applications that forestall the

308 evolution of resistance. For bacterial diseases, antibiotic resistance in pathogens of farmed fish 
309 also carries risks to human health, since the bacteria under selection on fish farms can exchange

310 genes with bacteria that affect humans (Cabello 2006). For example, molecular studies indicate

311 the genetic determinants of resistance to drugs like tetracycline, trimethoprim, sulfonamide and

312 streptomycin can and in some cases have been exchanged between the salmon pathogen

313 Aeromonas salmonicida and a variety of human pathogens including Vibrio cholerae,

314 Escherichia coli, Aeromonas hydrophila, and Aeromonas caviae (Cabello 2006). While wild fish

315 may ultimately be the origin of most infections of farmed fish, continued transmission between

316 wild and farmed fish may be important for the sustainability of health management practices in

317 aquaculture (Kreitzman et al. 2016). That is because wild fish provide a refuge from selection for

318 antibiotic resistance in parasites that also infect domesticated fish. Thus, maintaining genetic

319 connectivity between the domesticated fish and the wild refuge may be important for slowing or

320 stalling the evolution of resistance in parasites of domesticated fish.

\section{Management and innovation}

323 The challenges of infectious disease in fisheries and aquaculture have already spurred

324 innovations to control disease and promote fish health (Pohlenz and Gatlin 2014, Jones et al.

325 2015, Naslund and Johnsson 2016). The obvious example is the production of new pesticides,

326 medicines, and vaccines (Lorenzen and LaPatra 2005, Shoemaker et al. 2009). Some viral

327 diseases that previously caused epidemics in farmed fish are now effectively controlled with new

328 vaccines (Sommerset et al. 2005). Evolutionary responses of parasites to drug-based disease

329 control has led to treatment failure in some areas, further spurring the need for new drugs and

330 find alternative means of controlling disease and slowing parasite evolution. The idea that wild

331 fish may provide an evolutionary ecosystem service of slowing the emergence of drug resistance 
332 is not a formal part of management, yet the service may well explain why drug resistance in sea

333 lice has evolved in the North Atlantic but not the North Pacific (Kreitzman et al. 2016).

334 A move to coordinated area management recognizes that dispersal connects disease

335 dynamics among farms and between wild and farmed fish, and so parasite management on farms

336 is becoming increasingly coordinated at regional scales (Jones et al. 2015, Ellis et al. 2016).

337 Coordination of the timing of parasite treatment on farms to minimize parasite levels during

338 periods of wild fish migrations may effectively protect wild fish without increasing the overall

339 frequency of drug use (Peacock et al. 2013, Rogers et al. 2013).

340 Furthermore, knowledge from foodweb ecology has helped identify and implement

341 parasite control systems that include the co-stocking of cleaner fish, which consume parasites on

342 farmed fish, as well as multi-trophic aquaculture systems where filter feeders utilize the waste

343 from finfish farms, and kelp utilize the nutrient enrichment from both finfish and filter feeders

344 (Mordue and Pike 2002, Treasurer 2002). Domesticated fish populations have also become more

345 resistant to disease outbreaks via selective breeding as well as improved husbandry and site

346 selection that reduce sources of stress that can make fish more prone to disease (Pohlenz and

347 Gatlin 2014, Ellis et al. 2016, Naslund and Johnsson 2016).

\section{Conclusions}

350 The theory of parasite population biology indicates that numerous ecological and evolutionary

351 dynamics of parasites depend on host abundance and transmission between multiple host

352 populations, particularly wild and domesticated animals. There are therefore clear predictions

353 from theory as to the epidemiological consequences of aquaculture growth, which have

354 important implications for both wild and farmed fishes. Some predictions are already realized,

355 such as the evolution of drug resistance (Westcott et al. 2010), increased virulence (Sundberg et 
356 al. 2016), and density-dependent shifts from endemic to epizootic dynamics (Frazer et al. 2012).

357 Theory of disease risk and animal migration is clearly relevant for wild and farmed fish,

358 particularly aspects that elevate disease, such as migratory allopatry and stalling (Altizer et al.

359 2011), but the generality of these processes is not yet clear. Other aspects such as Allee effects or

360 evolutionary ecosystem services of slowing drug resistance remain mostly theoretical and

361 although they may mediate disease dynamics on farms, it is not clear to what extent they will be

362 taken up or be of practical use in management.

363 A key consideration not yet discussed is uncertainty. While theory provides clear

364 predictions as to the epidemiological consequences of aquaculture growth, it is much more

365 difficult to predict the details of where, when, and for whom EID will occur. For example, while

366 theory predicts continued emergences of virulent parasite strains it is not possible to presage the

367 exact details of timing, location, and extent because any true model of such dynamics would be

368 inherently stochastic. The issue of parameter uncertainty and parameter dependency on abiotic

369 variables also makes it difficult to make precise predictions, for example, when a host-density

370 threshold for a disease outbreak may be exceeded (Frazer et al. 2012). There is also an issue of

371 structural uncertainty in spatial scale, spatial structure, biological variables, or their interactions

372 so that it is not possible to know with certainty the exact model from which to make theoretical

373 predictions for particular contexts. Models will also vary among species, and a crux for future

374 research is to understand that variation to explain why only some parasites emerge as disease

375 problems for wild and farmed fish despite a diverse range of parasites that can be exchanged.

376 Nevertheless, while the theory of parasite population biology will necessarily fall short of

377 making precise predictions on epidemiological changes, it does provide an informative

378 framework for interpreting the causes of observed outbreaks, changes in pathogen traits,

379 management successes and failures, and future expectations (Peacock et al. 2013, Bateman et al. 

2016, Groner et al. 2016). This connection between theory and practice does not only point to

381 some utility for management but also opportunities to develop, test and refine theory. Looking

382 forward, both theory and empirical work suggest that a future of continued aquaculture growth

383 includes an intensification of ecological and evolutionary processes that facilitate disease

384 emergence. EID events in coastal seas with intensive aquaculture will likely continue with little

385 or no warning, and they will likely occur with increasing frequency, challenging innovation in

386 disease management to keep pace. Understanding and managing marine diseases will therefore

387 be critical to navigating towards a future for coastal seas in which prosperous aquaculture

388 activity coexists with productive coastal ecosystems and fisheries.

\section{Acknowledgements}

391 This paper was given as the Stevenson Lecture at the 2015 Canadian Conference for Fisheries

392 Research in Ottawa, January, 2015. I am grateful for that honour and opportunity. I owe thanks

393 to numerous colleagues, mentors, and students who have helped shape the ideas in this paper and

394 who have collaborated with me on many of the works cited. Brendan Connors and Andrew

395 Bateman provided helpful comments that improved the manuscript. This work was supported by 396 an NSERC Discovery Grant, Sloan Fellowship, and a Canada Research Chair.

\section{References}

399 Aldrin, M., B. Storvik, A. B. Kristoffersen, and P. A. Jansen. 2013. Space-Time Modelling of 400 the Spread of Salmon Lice between and within Norwegian Marine Salmon Farms. $401 \quad$ Plos One 8: e64039.

402 Altizer, S., R. Bartel, and B. A. Han. 2011. Animal migration and infectious disease risk. 403 Science 331:296-302.

404 Amundrud, T. L. and A. G. Murray. 2009. Modelling sea lice dispersion under varying 405 environmental forcing in a Scottish sea loch. Journal of Fish Diseases 32:27-44. 
406

407

408

409

410

411

412

413

414

415

416

417

418

419

420

421

422

423

424

425

426

427

428

429

430

431

432

433

434

435

436

437

438

439

440

441

442

443

444

445

446

447

448

449

450

451

Asche, F., H. Hansen, R. Tveteras, and S. Tveteras. 2009. The salmon disease crisis in Chile. Marine Resource Economics 24:405-411.

Bateman, A., S. Peacock, B. Connors, Z. Polk, D. Berg, M. Krkosek, and A. Morton. 2016. Recent failure in control of sea lice epizootics on juvenile wild salmon in the Broughton Archipelago, British Columbia. Canadian Journal of Fisheries and Aquatic Sciences 73:1164-1172.

Birkeland, K. and P. J. Jakobsen. 1997. Salmon lice, Lepeophtheirus salmonis, infestation as a causal agent of premature return to rivers and estuaries by sea trout, Salmo trutta, juveniles. Environmental Biology of Fishes 49:129-137.

Bradley, C. A. and S. Altizer. 2005. Parasites hinder monarch butterfly flight: implications for disease spread in migratory hosts. Ecology Letters 8:290-300.

Branch, T. A., R. Watson, E. A. Fulton, S. Jennings, C. R. McGilliard, G. T. Pablico, D. Ricard, and S. R. Tracey. 2010. The trophic fingerprint of marine fisheries. Nature 468:431435.

Bunce, A. and F. I. Norman. 2000. Changes in the diet of the Australasian gannet (Morus serrator) in response to the 1998 mortality of pilchards (Sardinops sagax). Marine and Freshwater Research 51:349-353.

Cabello, F. C. 2006. Heavy use of prophylactic antibiotics in aquaculture: a growing problem for human and animal health and for the environment. Environmental Microbiology 8:1137-1144.

Dann, P., F. I. Norman, J. M. Cullen, F. J. Neira, and A. Chiaradia. 2000. Mortality and breeding failure of little penguins, Eudyptula minor, in Victoria, 1995-96, following a widespread mortality of pilchard, Sardinops sagax. Marine and Freshwater Research 51:355-362.

Daszak, P., A. A. Cunningham, and A. D. Hyatt. 2000. Emerging infectious diseases of wildlife - Threats to biodiversity and human health. Science 287:443-449.

Day, T. 2001. Parasite transmission modes and the evolution of virulence. Evolution 55:2389-2400.

Day, T. and S. Gandon. 2007. Applying population-genetic models in theoretical evolutionary epidemiology. Ecology Letters 10:876-888.

Dobson, A. P. and R. M. May. 1987. The effects of parasites on fish populations - theoretical aspects. International Journal for Parasitology 17:363-370.

Duarte, C. M., N. Marbá, and M. Holmer. 2007. Rapid domestication of marine species. Science 316:382-383.

Ellis, T., J. F. Turnbull, T. G. Knowles, J. A. Lines, and N. A. Auchterlonie. 2016. Trends during development of Scottish salmon farming: An example of sustainable intensification? Aquaculture 458:82-99.

FA0. 2016. State of the world's fisheries and aquaculture. Food and Agricultural Organization of the United Nations, Rome.

Foreman, M. G. G., M. Guo, K. A. Garver, D. Stucchi, P. Chandler, D. Wan, J. Morrison, and D. Tuele. 2015. Modelling Infectious Hematopoietic Necrosis Virus Dispersion from Marine Salmon Farms in the Discovery Islands, British Columbia, Canada. Plos One 10.

Frazer, L. N., A. Morton, and M. Krkošek. 2012. Critical thresholds in sea lice epidemics: Evidence, sensitivity, and subcritical estimation. Proceedings of the Royal Society B 279:1950-1958. 
452

453

454

455

456

457

458

459

460

461

462

463

464

465

466

467

468

469

470

471

472

473

474

475

476

477

478

479

480

481

482

483

484

485

486

487

488

489

490

491

492

493

494

495

496

Garver, K. A., A. A. M. Mahony, D. Stucchi, J. Richard, C. Van Woensel, and M. Foreman. 2013. Estimation of Parameters Influencing Waterborne Transmission of Infectious Hematopoietic Necrosis Virus (IHNV) in Atlantic Salmon (Salmo salar). Plos One 8: e82296.

Gaughan, D. J., R. W. Mitchell, and S. J. Blight. 2000. Impact of mortality, possibly due to herpesvirus, on pilchard Sardinops sagax stocks along the south coast of Western Australia in 1998-99. Marine and Freshwater Research 51:601-612.

Gaughan, D. J. 2001. Disease-translocation across geographic boundaries must be recognized as a risk even in the absence of disease identification: the case with Australian Sardinops. Reviews in Fish Biology and Fisheries 11:113-123.

Goldburg, R. and R. Naylor. 2005. Future seascapes, fishing, and fish farming. Frontiers in Ecology and the Environment 3:21-28.

Grenfell, B. T. and A. P. Dobson. 1995. Ecology of Infectious Diseases in Natural Populations. Cambridge University Press, Cambridge.

Groner, M. L., G. Gettinby, M. Stormoen, C. W. Revie, and R. Cox. 2014. Modelling the Impact of Temperature-Induced Life History Plasticity and Mate Limitation on the Epidemic Potential of a Marine Ectoparasite. Plos One 9: e88465.

Groner, M. L., L. Rogers, A. Bateman, B. Connors, L. N. Frazer, S. Godwin, M. Krkosek, M. A. Lewis, S. Peacock, E. E. Rees, C. Revie, and U. Schlagel. 2016. Lessons from sea louse and salmon epidemiology. Philosophical Transactions of the Royal Society B 371:20150203.

Hall, R. J., S. Altizer, and R. A. Bartel. 2014. Greater migratory propensity in hosts lowers pathogen transmission and impacts. Journal of Animal Ecology 83:1068-1077.

Hatcher, M. J., J. T. A. Dick, and A. M. Dunn. 2012. Diverse effects of parasites in ecosystems: linking interdependent processes. Frontiers in Ecology and the Environment 10:186-194.

Jansen, P. A., A. B. Kristoffersen, H. Viljugrein, D. Jimenez, M. Aldrin, and A. Stien. 2012. Sea lice as a density-dependent constraint to salmonid farming. Proceedings of the Royal Society B-Biological Sciences 279:2330-2338.

Jones, J. B., A. D. Hyatt, P. M. Hine, R. J. Whittington, D. A. Griffin, and N. J. Bax. 1997. Australasian pilchard mortalities. World Journal of Microbiology \& Biotechnology 13:383-392.

Jones, S. R. M., D. W. Bruno, L. Madsen, and E. J. Peeler. 2015. Disease management mitigates risk of pathogen transmission from maricultured salmonids. Aquaculture Environment Interactions 6:119-134.

Kennedy, D. A., G. Kurath, I. L. Brito, M. K. Purcell, A. F. Read, J. R. Winton, and A. R. Wargo. 2016. Potential drivers of virulence evolution in aquaculture. Evolutionary Applications 9:344-354.

Kibenge, F. S. B., M. G. Godoy, Y. W. Wang, M. J. T. Kibenge, V. Gherardelli, S. Mansilla, A. Lisperger, M. Jarpa, G. Larroquete, F. Avendano, M. Lara, and A. Gallardo. 2009. Infectious salmon anaemia virus (ISAV) isolated from the ISA disease outbreaks in Chile diverged from ISAV isolates from Norway around 1996 and was disseminated around 2005, based on surface glycoprotein gene sequences. Virology Journal 6.

Kibenge, M. J. T., T. Iwamoto, Y. Wang, A. Morton, M. G. Godoy, and F. S. B. Kibenge. 2013. Whole-genome analysis of piscine reovirus (PRV) shows PRV represents a new 
genus in family Reoviridae and its genome segment S1 sequences group it into two separate sub-genotypes. Virology Journal 10:230.

Kibenge, M. J. T., T. Iwamoto, Y. W. Wang, A. Morton, R. Routledge, and F. S. B. Kibenge. 2016. Discovery of variant infectious salmon anaemia virus (ISAV) of European genotype in British Columbia, Canada. Virology Journal 13.

Kreitzman, M., J. Ashander, J. Driscoll, A. Bateman, K. Chan, M. A. Lewis, and M. Krkosek. 2016. An evolutionary ecosystem service: wild salmon sustain the effectiveness of parasite control on salmon farms. Conservation Letters Submitted.

Krkosek, M., J. Ashander, L. N. Frazer, and M. A. Lewis. 2013. Allee effect from parasite spillback. American Naturalist 182:640-652.

Krkošek, M., M. A. Lewis, and J. P. Volpe. 2005. Transmission dynamics of parasitic sea lice from farm to wild salmon. Proceedings of the Royal Society B 272:689-696.

Krkošek, M., M. A. Lewis, A. Morton, L. N. Frazer, and J. P. Volpe. 2006. Epizootics of wild fish induced by farm fish. Proceedings of the National Academy of Sciences of the USA 103:15506-15510.

Krkošek, M., A. Gottesfeld, B. Proctor, D. Rolston, C. Carr-Harris, and M. A. Lewis. 2007. Effects of host migration, diversity, and aquaculture on sea lice threats to Pacific salmon populations. Proceedings of the Royal Society B 274:3141-3149.

Krkošek, M., B. Connors, P. Mages, S. Peacock, H. Ford, J. S. Ford, A. Morton, J. P. Volpe, R. Hilborn, L. M. Dill, and M. A. Lewis. 2011. Fish farms, parasites, and predators: Implications for salmon population dynamics. Ecological Applications 21:897-914.

Krkošek, M., B. M. Connors, M. A. Lewis, and R. Poulin. 2012. Allee effects may slow the spread of parasites in a coastal marine ecosystem. American Naturalist 179:401412.

Lafferty, K. D., J. W. Porter, and S. E. Ford. 2004. Are diseases increasing in the ocean? Annual Review of Ecology Evolution and Systematics 35:31-54.

Lafferty, K. D., J. C. Shaw, and A. M. Kuris. 2008. Reef Fishes Have Higher Parasite Richness at Unfished Palmyra Atoll Compared to Fished Kiritimati Island. Ecohealth 5:338345.

Lafferty, K. D. 2009. The ecology of climate change and infectious diseases. Ecology 90:888900.

Lafferty, K. D., C. D. Harvell, J. M. Conrad, C. S. Friedman, M. L. Kent, A. M. Kuris, E. N. Powell, D. Rondeau, and S. M. Saksida. 2015. Infectious diseases affect marine fisheries and aquaculture economics. Annual Review of Marine Science 7:471-496.

Lloyd-Smith, J. O., P. C. Cross, C. J. Briggs, M. Daugherty, W. M. Getz, J. Latto, M. S. Sanchez, A. B. Smith, and A. Swei. 2005. Should we expect population thresholds for wildlife disease? Trends in Ecology and Evolution 20:511-519.

Lorenzen, N. and S. E. LaPatra. 2005. DNA vaccines for aquacultured fish. Revue Scientifique Et Technique-Office International Des Epizooties 24:201-213.

Marty, G. D., D. B. Morrison, J. Bidulka, T. Joseph, and A. Siah. 2015. Piscine reovirus in wild and farmed salmonids in British Columbia, Canada: 1974-2013. Journal of Fish Diseases 38:713-728.

May, R. M. 1977. Togetherness among schistosomes: Its effects on the dynamics of the infection. Mathematical Biosciences 35:301-343.

McCallum, H., D. Harvell, and A. Dobson. 2003. Rates of spread of marine pathogens. Ecology Letters 6:1062-1067. 
543

544

545

546

547

548

549

550

551

552

553

554

555

556

557

558

559

560

561

562

563

564

565

566

567

568

569

570

571

572

573

574

575

576

577

578

579

580

581

582

583

584

585

586

McCallum, H. I., A. Kuris, C. D. Harvell, K. D. Lafferty, G. W. Smith, and J. Porter. 2004. Does terrestrial epidemiology apply to marine systems? Trends in Ecology \& Evolution 19:585-591.

McLellan, B. N., R. Serrouya, H. U. Wittmer, and S. Boutin. 2010. Predator-mediated Allee effects in multi-prey systems. Ecology 91:286-292.

Mennerat, A., F. Nilsen, D. Ebert, and A. Skorping. 2010. Intensive Farming: Evolutionary Implications for Parasites and Pathogens. Evolutionary Biology 37:59-67.

Mennerat, A., L. Hamre, D. Ebert, F. Nilsen, M. Davidova, and A. Skorping. 2012. Life history and virulence are linked in the ectoparasitic salmon louse Lepeophtheirus salmonis. Journal of Evolutionary Biology 25:856-861.

Molnar, P. K., S. J. Kutz, B. M. Hoar, and A. P. Dobson. 2013. Metabolic approaches to understanding climate change impacts on seasonal host-macroparasite dynamics. Ecology Letters 16:9-21.

Mordue, A. J. and A. W. Pike. 2002. Salmon farming: towards an integrated pest management strategy for sea lice. Pest Management Science 58:513-514.

Myers, R. A. and B. Worm. 2003. Rapid worldwide depletion of predatory fish communities. Nature 423:280-283.

Naslund, J. and J. I. Johnsson. 2016. Environmental enrichment for fish in captive environments: effects of physical structures and substrates. Fish and Fisheries 17:130.

Nematollahi, A., A. Decostere, F. Pasmans, and F. Haesebrouck. 2003. Flavobacterium psychrophilum infections in salmonid fish. Journal of Fish Diseases 26:563-574.

Nowak, B. F. 2007. Parasitic diseases in marine cage culture - An example of experimental evolution of parasites? International Journal for Parasitology 37:581-588.

O'Connor, M. I., J. F. Bruno, S. D. Gaines, B. S. Halpern, S. E. Lester, B. P. Kinlan, and J. M. Weiss. 2007. Temperature control of larval dispersal and the implications for marine ecology, evolution, and conservation. Proceedings of the National Academy of Sciences of the United States of America 104:1266-1271.

Palacios, G., M. Lovoll, T. Tengs, M. Hornig, S. Hutchison, J. Hui, R. T. Kongtorp, N. Savji, A. V. Bussetti, A. Solovyov, A. B. Kristoffersen, C. Celone, C. Street, V. Trifonov, D. L. Hirschberg, R. Rabadan, M. Egholm, E. Rimstad, and W. I. Lipkin. 2010. Heart and skeletal muscle inflammation of farmed salmon is associated with infection with a novel Reovirus. Plos One 5.

Pauly, D., V. Christensen, J. Dalsgaard, R. Froese, and F. Torres. 1998. Fishing down marine food webs. Science 279:860-863.

Peacock, S., M. Krkošek, S. Proboszcz, C. Orr, and M. A. Lewis. 2013. Cessation of a salmon decline with control of parasites. Ecological Applications 23:206-220.

Peacock, S., B. Connors, M. Krkosek, J. Irvine, and M. A. Lewis. 2014. Can reduced predation offset negative effects of sea louse parasites on chum salmon? Proceedings of the Royal Society B 281:20132913.

Peacock, S. J., M. Krkosek, A. W. Bateman, and M. A. Lewis. 2015. Parasitism and food web dynamics of juvenile Pacific salmon. Ecosphere 6.

Pohlenz, C. and D. M. Gatlin. 2014. Interrelationships between fish nutrition and health. Aquaculture 431:111-117. 
587

588

589

590

591

592

593

594

595

596

597

598

599

600

601

602

603

604

605

606

607

608

609

610

611

612

613

614

615

616

617

618

619

620

621

622

623

624

625

626

627

628

629

630

Pulkkinen, K., L. R. Suomalainen, A. F. Read, D. Ebert, P. Rintamaki, and E. T. Valtonen. 2010. Intensive fish farming and the evolution of pathogen virulence: the case of columnaris disease in Finland. Proceedings of the Royal Society B 277:593-600.

Regoes, R. R., D. Ebert, and S. Bonhoeffer. 2002. Dose-dependent infection rates of parasites produce the Allee effect in epidemiology. Proceedings of the Royal Society B 269:271-279.

Rogers, L., S. Peacock, P. McKenzie, S. DeDominicis, S. Jones, P. Chandler, M. G. G. Foreman, C. Revie, and M. Krkošek. 2013. Modeling parasite dynamics on farmed salmon for precautionary conservation management of wild salmon. Plos One 8:e60096.

Shoemaker, C. A., P. H. Klesius, J. J. Evans, and C. R. Arias. 2009. Use of Modified Live Vaccines in Aquaculture. Journal of the World Aquaculture Society 40:573-585.

Sommerset, I., B. Krossoy, E. Biering, and P. Frost. 2005. Vaccines for fish in aquaculture. Expert Review of Vaccines 4:89-101.

Stucchi, D. J., M. Guo, M. G. G. Foreman, P. Czajko, M. Galbraith, D. L. Mackas, and P. A. Gillibrand. 2011. Modeling sea lice production and concentrations in the Broughton Archipelago, British Columbia.in S. Jones and R. Beamish, editors. Salmon Lice: An integrated appropach to understanding parasite abundance and distribution. WileyBlackwell, Chichester.

Sundberg, L. R., T. Ketola, E. Laanto, H. Kinnula, J. K. H. Bamford, R. Penttinen, and J. Mappes. 2016. Intensive aquaculture selects for increased virulence and interference competition in bacteria. Proceedings of the Royal Society B-Biological Sciences 283.

Tompkins, D. M., S. Carver, M. E. Jones, M. Krkošek, and L. F. Skerratt. 2015. Emerging infectious diseases of wildlife: a critical perspective. Trends in Parasitology 31:149159.

Treasurer, J. W. 2002. A review of potential pathogens of sea lice and the application of cleaner fish in biological control. Pest Management Science 58:546-558.

Vollset, K. W., B. T. Barlaup, H. Skoglund, E. S. Normann, and O. T. Skilbrei. 2014. Salmon lice increase the age of returning Atlantic salmon. Biology Letters 10.

Walker, P. J. and J. R. Winton. 2010a. Emerging viral diseases of fish and shrimp. Veterinary Research 41.

Walker, P. J. and J. R. Winton. 2010b. Emerging viral diseases of fish and shrimp. Veterinary Research 41:51-75.

Walters, C. 2003. Folly and fantasy in the analysis of spatial catch rate data. Canadian Journal of Fisheries and Aquatic Sciences 60:1433-1436.

Ward, J. R. and K. D. Lafferty. 2004. The elusive baseline of marine disease: Are diseases in ocean ecosystems increasing? Plos Biology 2:542-547.

Ward, T. M., F. Hoedt, L. McLeay, W. F. Dimmlich, G. Jackson, P. J. Rogers, and K. Jones. 2001a. Have recent mass mortalities of the sardine Sardinops sagax facilitated an expansion in the distribution and abundance of the anchovy Engraulis australis in South Australia? Marine Ecology-Progress Series 220:241-251.

Ward, T. M., F. Hoedt, L. McLeay, W. F. Dimmlich, M. Kinloch, G. Jackson, R. McGarvey, P. J. Rogers, and K. Jones. 2001b. Effects of the 1995 and 1998 mass mortality events on the spawning biomass of sardine, Sardinops sagax, in South Australian waters. Ices Journal of Marine Science 58:865-875. 
631 Westcott, J. D., C. W. Revie, B. L. Griffin, and K. L. Hammell. 2010. Evidence of sea lice Lepeophtheirus salmonis tolerance to emamectin benzoate in New Brunswick Canada. Sea Lice 2010 - 8th International Sea Lice Conference, Victoria, BC. fishing on rates of parasitism in the ocean. Ecology Letters 13:761-775.

Worm, B., R. Hilborn, J. K. Baum, T. A. Branch, J. S. Collie, C. Costello, M. J. Fogarty, E. A. Fulton, J. A. Hutchings, S. Jennings, O. P. Jensen, H. K. Lotze, P. M. Mace, T. R. McClanahan, C. Minto, S. R. Palumbi, A. M. Parma, D. Ricard, A. A. Rosenberg, R. Watson, and D. Zeller. 2009. Rebuilding global fisheries. Science 325:578-585. 
645 Figure 1.

646
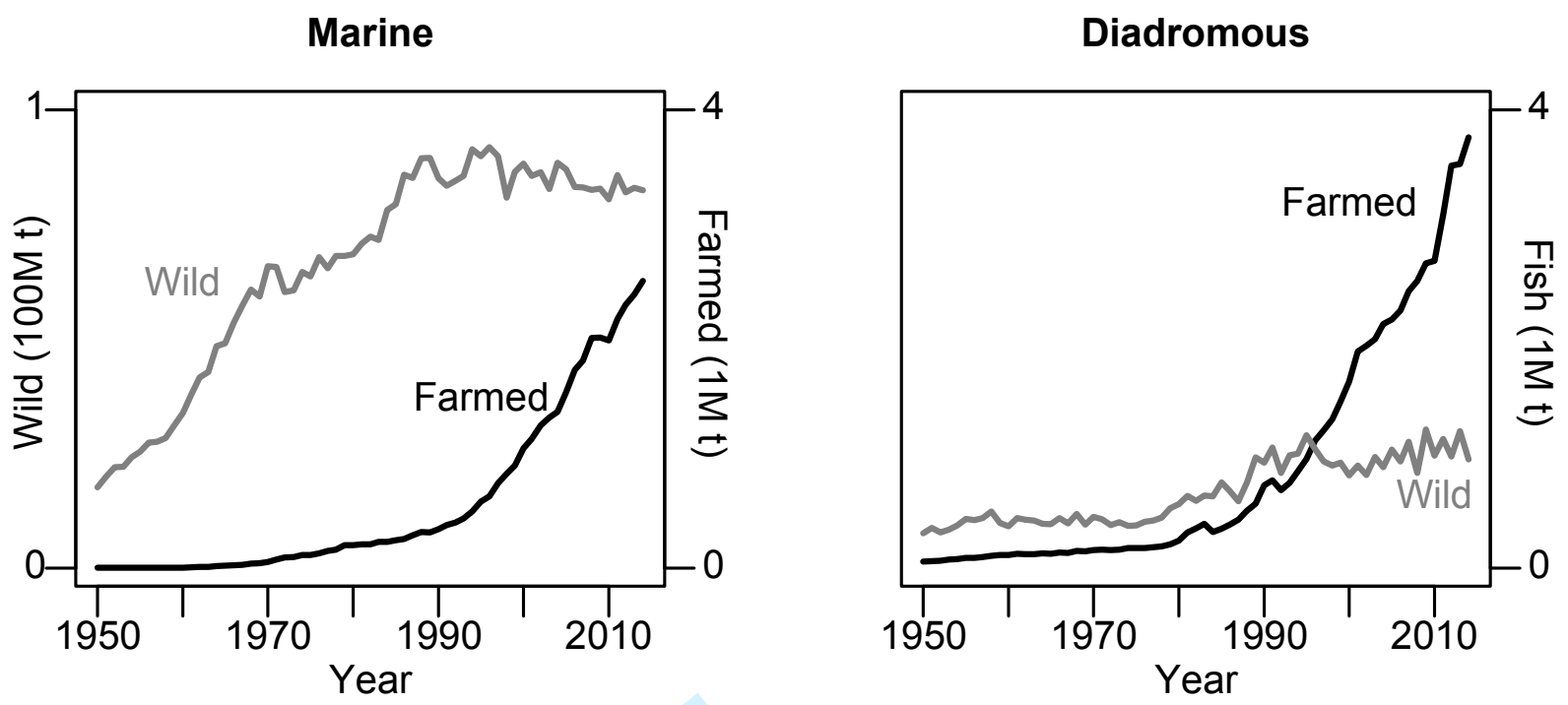

648

649 Figure 1. Global production from fisheries and aquaculture of marine (left panel) and

650 diadromous (right panel) fish in marine and brackish waters. The diadromous panel excludes

651 marine and freshwater fishes and the marine panel excludes diadromous and freshwater fishes.

652 Note that the $y$-axis scale for marine fish differs between wild and farmed fish but is the same for

653 diadromous fish of wild and farmed origin. Data source: (FAO 2016).

654

655

656 
657 Figure 2
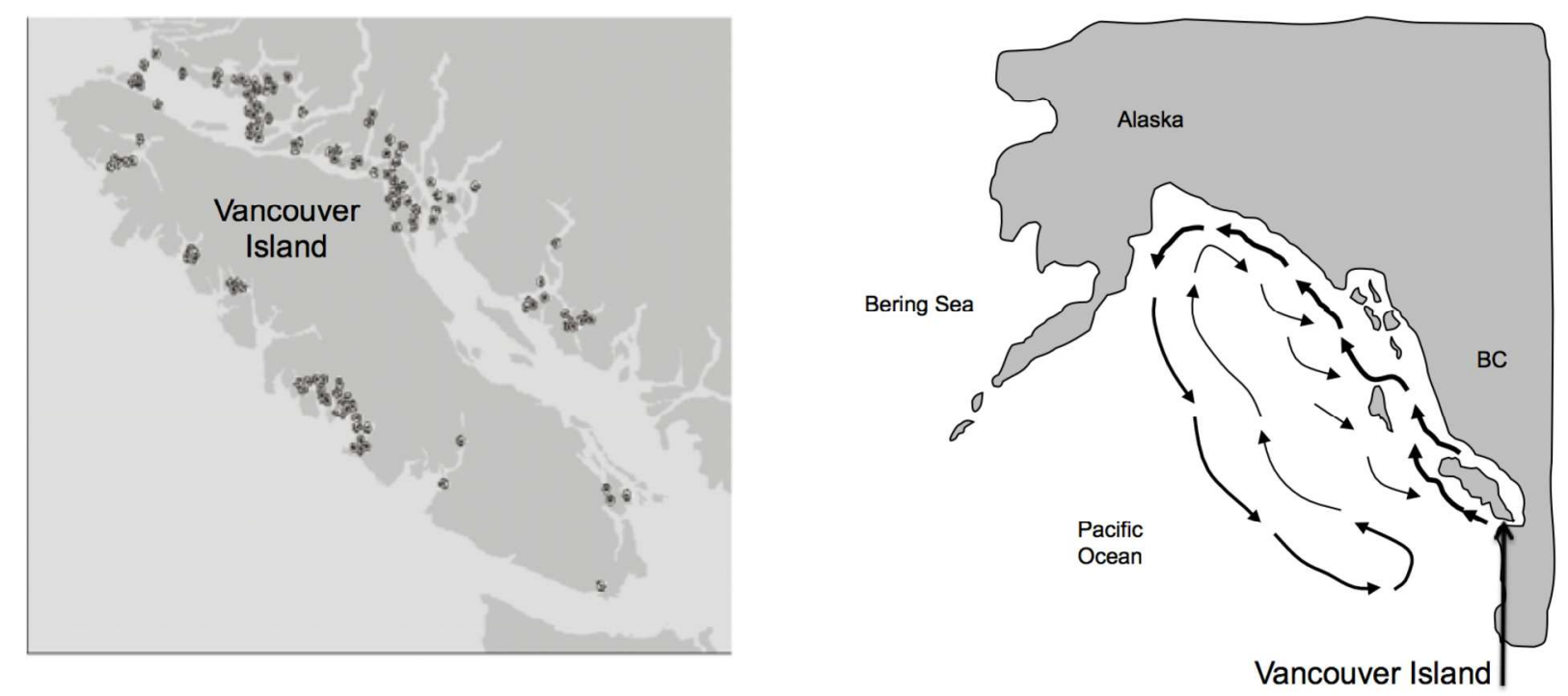

660 Figure 2. Distribution of salmon farm tenures (left) around Vancouver Island, British Columbia and the migration of wild pink salmon from the Fraser River (right). Parasite dispersal connects the population dynamics of disease amongst farms within a region as well as between farmed

663 salmon and the wild salmon populations that migrate through the aquaculture regions as

664 juveniles and as adults.

665

666

667 


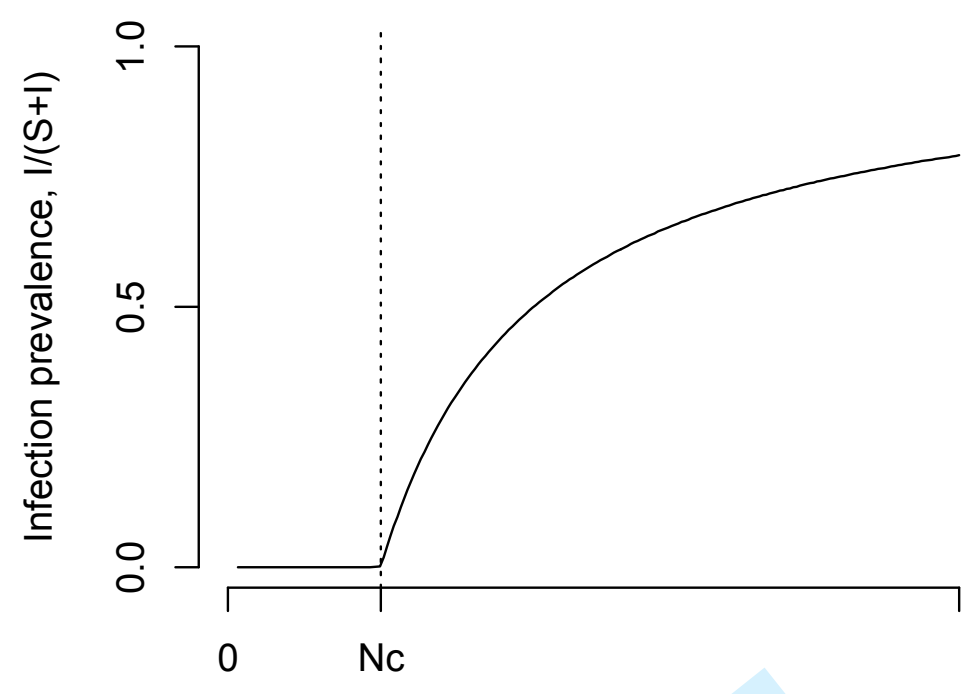

Abundance of farmed fish, $\mathrm{S}+\mathrm{I}$

670 Figure 3. Equilibrium levels of infection prevalence as a function of farmed fish abundance predicted by a susceptible-infected model. At abundances below the host-density threshold $(N c)$ infection is at a low (non-zero) endemic state, maintained by immigration of parasites from the surrounding environment. At abundances above the host density threshold, the dynamics switch to epidemic conditions where infection can be sustained and spread within the farmed fish population. Above $N c$, equilibrium levels of infection sharply increase as a function of farmed fish abundance and eventually saturate at $100 \%$. The model: Farmed fish are categorized into susceptible $(S)$ and infected $(I)$ classes. New fish are stocked into the production system at rate $\psi$, infected individuals transmit the parasite to new hosts at rate $\beta$, and infection enters the domesticated environment from an external (wild) reservoir host population at rate $\gamma$. The natural mortality plus harvest rate of fish is $\mu$ and the rate of parasite induced host mortality is $\alpha$. The $S-I$ dynamics can be characterized by the equations $\frac{d S}{d t}=\psi-\beta S I-\gamma S-\mu S$ and $\frac{d I}{d t}=\beta S I+\gamma S-$ $(\mu+\alpha) I$. The net reproductive value, $R_{0}$, which is the average number of secondary infections in a completely susceptible population caused, on average, by an initial infection is $R_{0}=$ $\beta N /(\mu+\alpha)$ where $N$ is the size of the host population when all hosts are susceptible prior to disease introduction. The critical host density threshold that divides endemic versus epizootic dynamics is found by solving for $N$ when $R_{0}=1$, which gives $N_{c}=(\mu+\alpha) / \beta$. The equilibrium expressions for susceptible and infected hosts are given implicitly as $S^{*}=\psi /\left(\beta I^{*}+\gamma+\mu\right)$ and $I^{*}=\gamma S^{*} /\left(\mu+\alpha-\beta S^{*}\right)$. Parameter values used for this plot are $\psi=0.01$ to 1 (controls the total fish abundance along the $\mathrm{x}$-axis), $\beta=0.001, \mu=0.01, \alpha=0.005$, and $\gamma=0.0000001$. 
691 Figure 4.
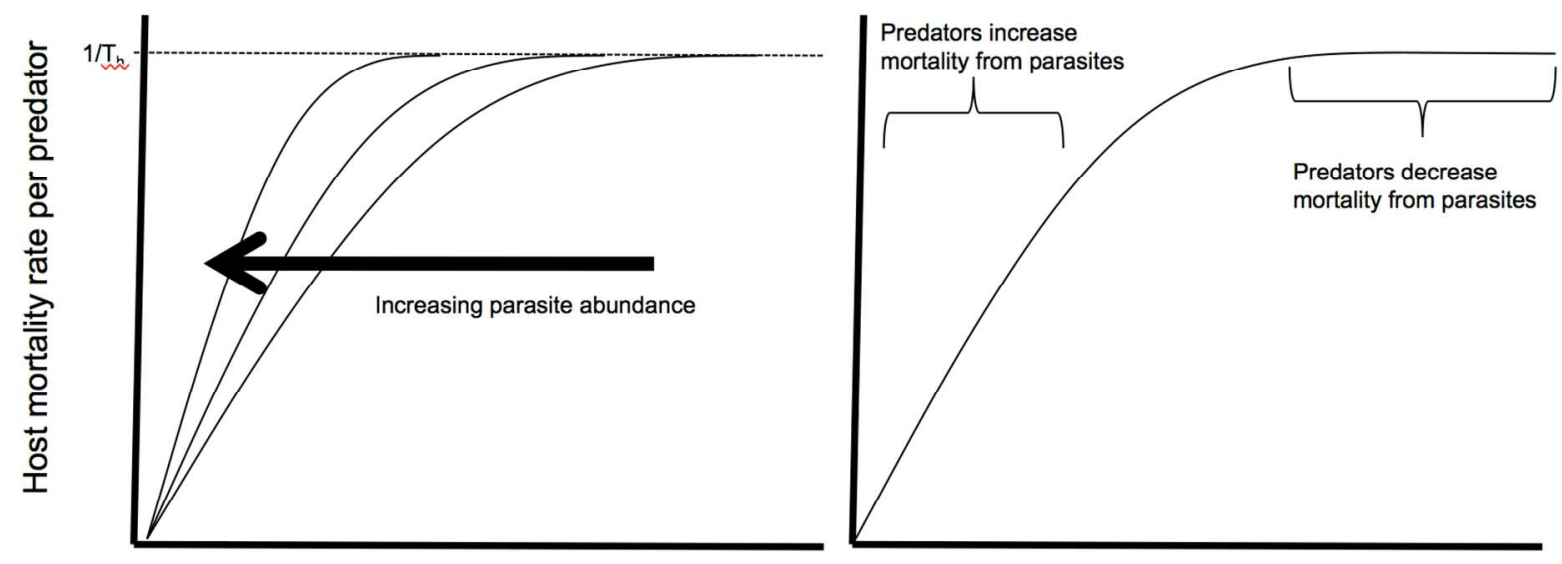

Host abundance

693 Figure 4. Functional response of a predator when its attack rate is an increasing function of 694 parasite abundance (Krkošek et al. 2011). The functional response is given by $(\gamma+p \theta) N /[1+$ $\left.695(\gamma+p \theta) T_{h} N\right]$ where $\gamma$ is the base attack rate of a predator on prey in the absence of parasites, $p$ 696 is the average abundance of parasites, $\theta$ is the per-parasite rate of increased attack rate of the 697 predator on the prey, $T_{h}$ is the handling time, and $N$ is the abundance of the prey population. In 698 the model, increasing levels of parasite abundance cause the functional response curve to rise 699 more quickly but do not change the saturation level of prey consumption. The result is that at low prey abundance, predation indirectly intensifies mortality arising from parasites whereas at high

701

702 prey abundance predation rates are unaffected by parasite levels but instead become focused on 703 the infected portion of the prey population. 

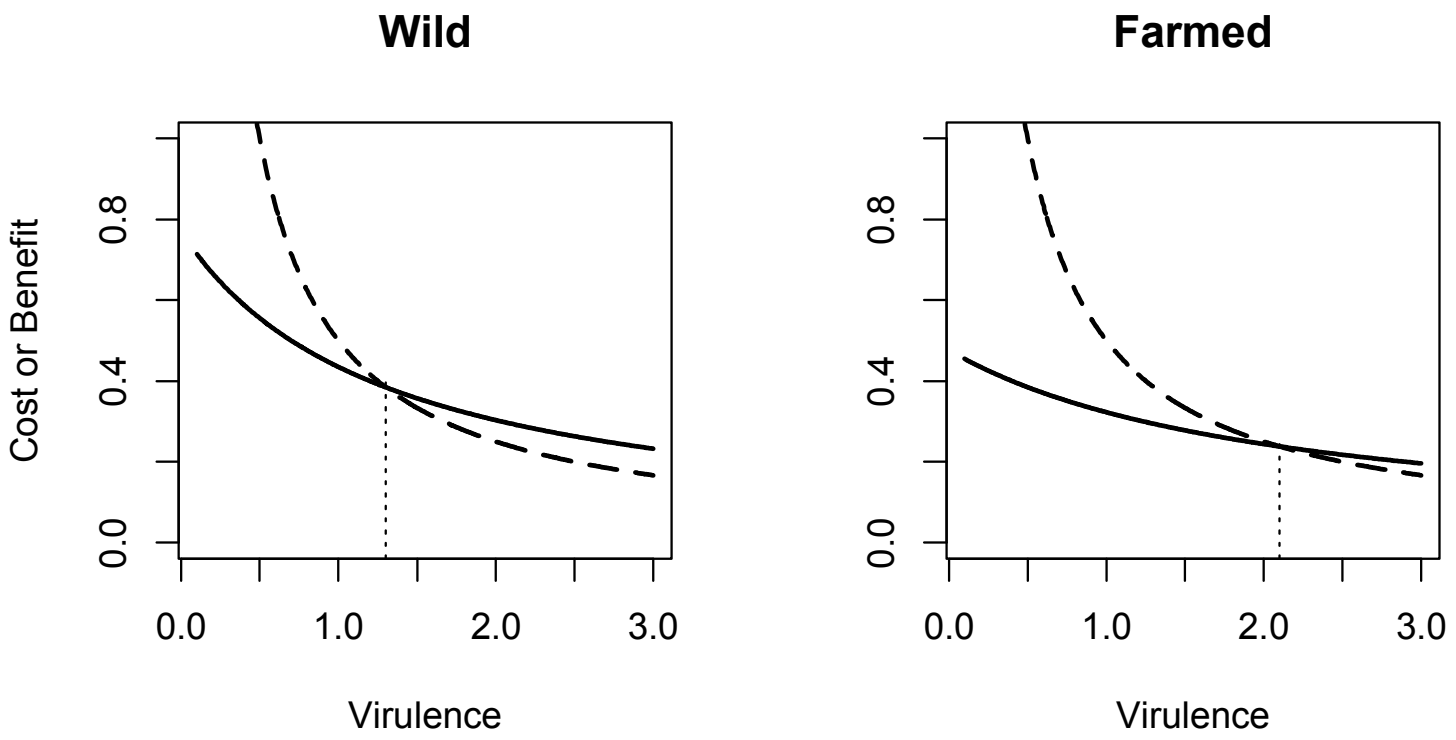

707 Figure 5. Simple model of how virulence may change for a parasite in wild versus farmed fish conditions. The model assumes that both transmission $\beta$ and host mortality $\psi$ are functions of virulence $\alpha$, where virulence is proportional to the rate of host-exploitation of the parasite resulting in increased parasite propagules being produced (increasing $\beta$ ) but at the expense of host mortality (increasing $\psi$ ). A measure of the fitness of the parasite is the net reproductive value, $R_{0}$ (i.e., the number of secondary infections generated by a single infection in a susceptible host population), and so $R_{0}=[\beta(\alpha) / \psi(\alpha)] S$, where $S$ is the abundance or density of susceptible hosts. Optimizing parasite fitness over virulence (i.e. $\left.d R_{0} / d \alpha=0\right)$ gives the evolutionary stable strategy for the virulence trait when $(1 / \beta)(d \beta / d \alpha)=(1 / \psi)(d \psi / d \alpha)$ where the benefit to increased transmission of increasing virulence $((1 / \beta)(d \beta / d \alpha)$, dashed lines) equals the cost to increased host mortality of increasing virulence $((1 / \psi)(d \psi / d \alpha)$, solid lines). The benefit curve is hypothesized to be steeper and the cost curve shallower in domesticated environments relative to wild environments due to the lack of migration, predation, and food limitation in domesticated environments. Such shifts in the trade-off curves cause the evolutionary equilibrium of the virulence trait to shift to the right (vertical dotted lines). 
Page 29 of 33 CAhartian Journal of Fisheries and AquatiBisdienouss

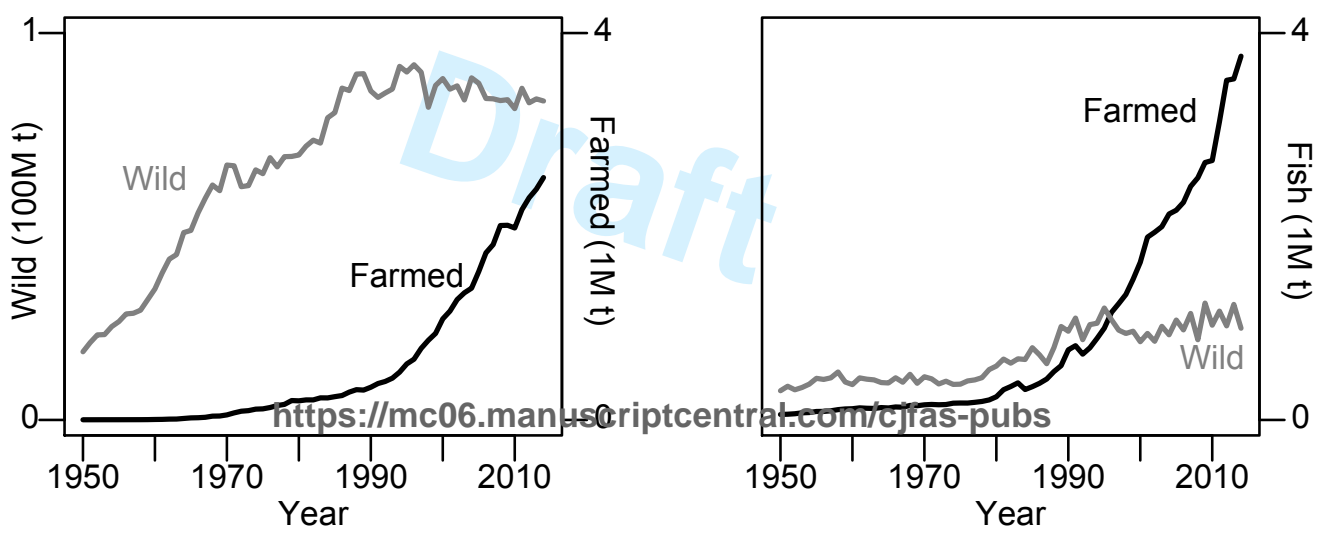



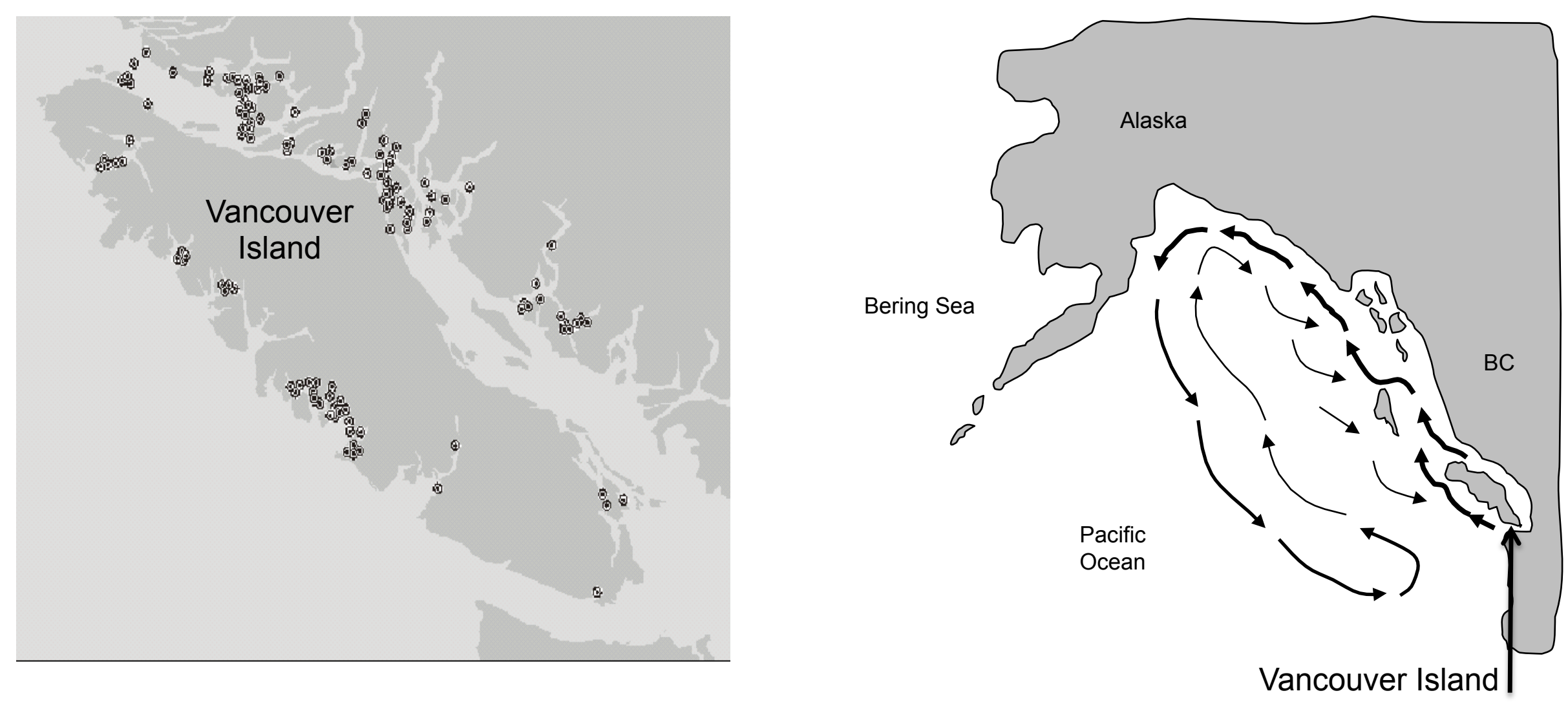

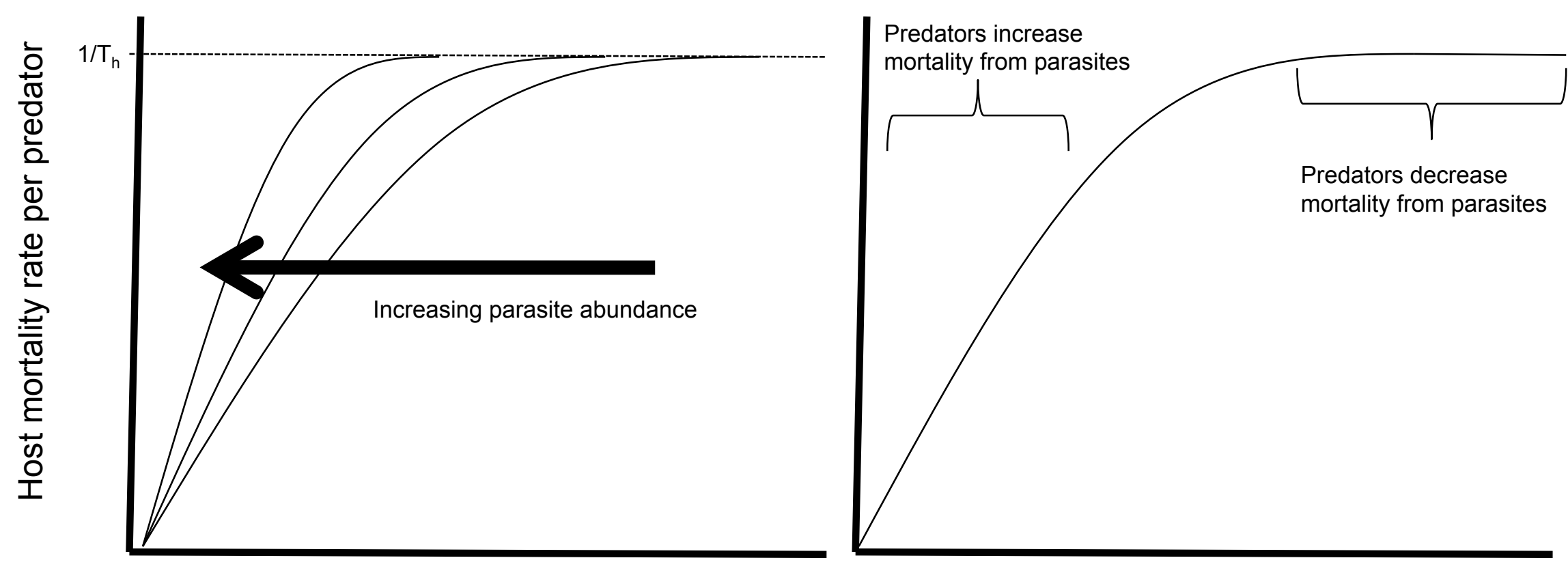

Host abundance 
